\title{
AVALIAÇÃO FÍSICO-QUÍMICA, MICROBIOLÓGICA E SENSORIAL DE QUEIJO MINAS FRESCAL DE LEITE DE CABRA DESENVOLVIDO POR ACIDIFICAÇÃO DIRETA E FERMENTAÇÃO LÁTICA
}

\section{Evaluation physicochemical, microbiological and sensory of Minas frescal goat milk cheese developed for direct acidification and lactic acid fermentation}

\begin{abstract}
Keily Alves de Moura Oliveira ${ }^{*}$, Denyse Moraes Jardim ${ }^{I}$, Karina da Silva Chaves ${ }^{2}$, Glauco Vieira de Oliveiral ${ }^{\prime}$ Márcia Cristina Teixeira Ribeiro Vidigal ${ }^{1}$
\end{abstract}

\section{RESUMO}

O objetivo deste estudo foi avaliar o efeito da acidificação direta por ácido lático e por adição de cultura starter mesofílica tipo O (Lactococcus lactis subsp. lactis e Lactococcus lactis subsp. cremoris) nas propriedades físico-químicas, microbiológicas e sensoriais de queijo Minas frescal de leite de cabra. Duas formulações de queijo Minas frescal foram elaboradas por acidificação com ácido lático e com cultura mesofílica tipo $\mathrm{O}$ e avaliadas quanto a qualidade microbiológica, quantificando $S$. aureus, psicrotróficos, bactérias láticas, coliformes termotolerantes e quanto a presença de Salmonella sp. Quanto as análises físico-químicas, foram realizadas determinação de gordura, cinzas, umidade, acidez titulável em ácido lático e pH. As modificações físico-químicas no queijo Minas frescal foram avaliadas durante o período de estocagem de 14 dias e analisada a sua aceitabilidade e intenção de compra por meio da avaliação sensorial. Os resultados revelaram que ambas as formulações do queijo Minas frescal apresentavam-se em boas condições higiênico-sanitárias e de consumo. Quanto aos parâmetros físico-químicos, os teores de gordura, cinzas e umidade dos queijos não diferiram significativamente entre si $(\mathrm{p}<0,05)$. O queijo obtido por acidificação direta por ácido lático foi o

1 Universidade Federal do Mato Grosso (UFMT), Campus Universitário do Araguaia, Av. Valdon Varjão, 6390, Bairro Industrial, 78600-000, Barra do Garças, MT, Brasil. Email: keilyam@yahoo.com.br

2 Universidade Federal de Campina Grande, Campina Grande, PB, Brasil.

* Autor para correspondência. 
que apresentou menor contagem de bactérias láticas totais e acidez, maior valor de $\mathrm{pH}$ e maior aceitabilidade sensorial e intenção de compra diferindo do queijo obtido por fermentação lática. Os resultados mostram que a forma de acidificação afeta as características do produto e sua aceitação pelos consumidores. A utilização do leite de cabra para produção do queijo Minas frescal apresenta potencial de aplicação na indústria de lácteos, agrega valor, tornando-o um produto alternativo aos consumidores alérgicos ao leite bovino.

Palavras-chave: ácido lático; cultura starter; leite de cabra; queijo Minas frescal.

\begin{abstract}
The aim of this study was to evaluate the effect of the direct acidification by lactic acid and indirect, by adding of the mesophilic starter culture type $\mathrm{O}$ (Lactococcus lactis subsp. lactis e Lactococcus lactis subsp. cremoris), the physicochemical properties, microbiological and sensory product. Two formulations of Minas Frescal cheese were prepared by acidification with lactic acid and acidification with mesophilic type $\mathrm{O}$ culture and evaluated for microbiological quality: the psychrotrophic count, aerobic mesophilic and thermotolerant Coliforms and Salmonella sp. The physicochemical analyzes were performed determination of fat, ash, moisture, acidity in lactic acid and $\mathrm{pH}$. The physical and chemical changes were evaluated in the Minas fresh cheese during the 14-day storage period, and analyzed its acceptability and purchase intent through sensory analysis. The results revealed that the Minas fresh cheese formulations presented in good sanitary conditions and of consumption. The physico-chemical parameters of fat, ash and moisture of the Minas fresh cheeses do not differ significantly $(\mathrm{p}<0.05)$. The cheese obtained by direct acidification by lactic acid showed the lowest values of count total lactic bacteria and acidity in acid lactic, higher $\mathrm{pH}$ and greater sensory acceptance and purchase intent differing cheese obtained by lactic fermentation. The results show that the form of acidification affects the product characteristics and consumer acceptability. The use of goat milk for the production of fresh cheese mines shows potential for the dairy industry and adds value to the product and becomes an alternative product to consumers allergic to cow's milk.
\end{abstract}

Keywords: acid lactic; starter culture; goat milk; Minas fresh cheese.

\section{INTRODUÇÃO}

O queijo Minas frescal apresenta um processamento simples e rápido, com alto rendimento e representa cerca de $5,2 \%$ da produção nacional (QUEIROGA et al., 2009; ROSA, 2004; SCOT CONSULTORIA, 2014). Segundo o Ministério da Agricultura, Pecuária e Abastecimento, por meio da Portaria n 352
(BRASIL, 1997), o queijo Minas frescal é definido como um queijo fresco obtido por coagulação enzimática do leite com coalho e/ou outras enzimas coagulantes apropriadas, complementada ou não com ação de bactérias láticas específicas. É considerado um queijo semi-gordo ( $25 \%$ a $44 \%$ de gordura na matéria seca), de alta umidade (não inferior a 55\%) e deve ser consumido fresco (BRASIL, 1996). 
Este apresenta o $\mathrm{pH}$ em torno de 5,0, baixa quantidade de sal e ausência de conservantes (BURITI et al., 2005).

As bactérias láticas são comumente utilizadas na produção de queijos como culturas starter, promovendo a acidificação com a produção de ácido lático, acelerando a coagulação do leite e, contribuindo também, para o desenvolvimento de sabor, aroma e textura do queijo produzido. Contudo, a acidificação direta do leite pela adição do ácido lático industrial também tem sido utilizada pelos laticínios. A acidificação do queijo utilizando ácido lático é outra forma de melhorar as características de produção e de preservação, diminuindo as alterações qualitativas ao longo do tempo de estocagem (ALVES et al., 2011).

Existe a algum tempo grande interesse na produção de leite de cabra, que cresce em importância quando se conhece o seu valor nutricional e a possibilidade de mercado consumidor para o leite e seus derivados (CORREIA; BORGES, 2009). O leite de cabra é reconhecido pelas suas propriedades hipoalergênicas e vem sendo amplamente incorporado à dieta infantil, especialmente voltado às crianças alérgicas às proteínas do leite bovino, devendo-se ao fato de suas proteínas, em sua maioria, compostas por $\beta$-caseína, $\alpha$-s2-caseína e, em menor quantidade, de $\alpha$-s1-caseína, fração muito associada a alergias infantis (PARK, 2009). Outro efeito benéfico associado ao consumo do leite de cabra é a sua digestibilidade que é facilitada pelo tamanho reduzido e fácil dispersão dos seus glóbulos de gordura e pela sua proteína coagulável que forma uma coalhada fina, macia e com boa digestão (COELHO, 2012). Além disso, o consumo do leite de cabra tem sido indicado para pacientes em tratamento da síndrome de má absorção de nutrientes e distúrbios intestinais, devido a sua composição dos ácidos capróico, caprílico e cáprico que são duas vezes superiores às do leite bovino
(ALFÉREZ et al., 2001). Assim, os produtos lácteos derivados de leite de cabra, como o queijo tipo Minas frescal, representam uma alternativa economicamente promissora para a cadeia produtiva da caprinocultura leiteira em decorrência da agregação de valor e potencial aumento de consumo de produtos dessa origem (SANTOS et al., 2009).

Neste contexto, o objetivo deste trabalho foi avaliar o efeito da acidificação direta por ácido lático e por adição da cultura starter mesofílica tipo $\mathrm{O}$ (Lactococcus lactis subsp. lactis e Lactococcus lactis subsp. cremoris), nas propriedades físico-químicas, microbiológicas e sensoriais do queijo Minas frescal a base de leite de cabra.

\section{MATERIAL E MÉTODOS}

\section{Processo de produção e preparo das formulações}

Para produção do queijo Minas frescal foi utilizado leite de cabra in natura fornecido por um produtor da cidade de Barra do Garças - MT.

\section{Produção do queijo Minas Frescal}

\section{Preparo da cultura}

A cultura starter mesofílica tipo $\mathrm{O}$ (Lactococcus lactis subsp. lactis e Lactococcus lactis subsp. cremoris) (R-704, Chr. Hansen, Valinhos, SP, Brasil) foi propagada em leite em pó reconstituído $(10 \%, \mathrm{~m} / \mathrm{v})$, por 16 horas a $35{ }^{\circ} \mathrm{C}$, e utilizadas na fabricação dos queijos na quantidade de $1 \%, \mathrm{v} / \mathrm{v}$.

\section{Produção do queijo Minas frescal}

Os queijos foram produzidos confome método descrito por Santos et al. (2009) com modificações, em três repetições. Para cada processo, $12 \mathrm{~L}$ de leite integral de cabras 
foram tratados termicamente $\left(68{ }^{\circ} \mathrm{C}\right.$ por 2 min) (VIANNA et al., 2008; ALVES et al., 2013; CHAVES; GIGANTE, 2016), resfriados a $35{ }^{\circ} \mathrm{C}$, divididos em 2 porções (6 litros) utilizadas para a fabricação do queijo Minas frescal de acordo com os seguintes tratamentos: (T1) queijo Minas frescal com adição de ácido lático a concentração de $85 \%$ $(2,5 \mathrm{~mL} / 10 \mathrm{~L})$ e (T2) queijo Minas frescal com a adição de $1 \%(\mathrm{v} / \mathrm{v})$ de cultura láctica constituída de Lactococcus lactis ssp. lactis e Lactococcus lactis ssp. cremoris. Após adição da cultura láctica e do ácido lático, adicionou-se o cloreto de cálcio (solução a 50\%, $\mathrm{m} / \mathrm{v}$ ) na proporção de $4 \mathrm{~mL}$ para $10 \mathrm{~L}$ de leite e coagulante (Há-La 1175, Chr. Hansen, Valinhos, SP, Brasil) (força do coagulante 1:3000), aguardando o tempo de coagulação de 25 minutos a $35^{\circ} \mathrm{C}$. O coágulo obtido foi cortado em cubos de $1 \mathrm{~cm}$ de aresta e mantido sob agitação durante 20 minutos. Após o ponto de massa, o soro foi drenado, aproximadamente $90 \%$, e adicionou-se o cloreto de sódio ( $80 \mathrm{~g} / 10 \mathrm{~L})$ e agitação da massa por 5 minutos, seguindo-se da enformagem e viragens alternadas a cada 20 minutos, por 1 hora em temperatura ambiente. Após a esse período, os queijos foram para refrigeração $\left(4{ }^{\circ} \mathrm{C} \pm 1\right)$ durante 16 horas para continuar a dessoragem. Ao final, os queijos foram embalados e armazenados a $4{ }^{\circ} \mathrm{C}$ por 21 dias.

\section{Análises Físico-Químicas}

No leite de cabra avaliou-se o $\mathrm{pH}(\mathrm{pH}$ meter DMPH-2-Digimed, São Paulo, SP, Brasil), acidez titulável em ácido lático, cinzas e densidade. O teor gordura foi determinado pelo método de Gerber (British Standard Institution, 1989). As análises físico-químicas realizadas nas amostras de queijo Minas frescal foram: determinação de gordura, cinzas, umidade. Todas estas análises foram realizadas conforme as metodologias recomendadas pelo Instituto Adolfo Lutz (2005).

\section{Análises Microbiológicas}

O leite de cabra foi avaliado quanto à contagem de coliformes termotolerantes, Salmonella sp., psicrotróficos e aeróbios mesófilos. Já os queijos foram avaliados quanto à contagem de coliformes termotolerantes, Salmonella sp., psicrotróficos, S. aureus.

Todas as análises microbiológicas foram realizadas conforme as metodologias recomendadas pela American Public Health Association (APHA, 2001).

\section{Vida de prateleira do queijo Minas frescal}

Após 1, 7 e 14 dias de armazenamento refrigerado, os queijos foram avaliados quanto ao $\mathrm{pH}$, acidez titulável e determinação de bactérias láticas totais. $\mathrm{O} \mathrm{pH}$ foi determinado introduzindo-se o eletrodo diretamente na amostra (pH meter DMPH-2-Digimed, São Paulo, SP, Brasil) e a acidez foi determinada de acordo com o método descrito pelo Instituto Adolfo Lutz (2005). A contagem de bactérias láticas foi enumerada por meio de plaqueamento em profundidade em ágar MRS e incubada em anaerobiose a $37^{\circ} \mathrm{C}$ por 48 horas (APHA, 2001).

\section{Análise Sensorial}

A avaliação sensorial das amostras de queijo Minas frescal produzido com leite de cabra foi realizada por meio do teste de aceitação em relação à impressão global, aroma, cor, sabor e textura utilizando uma escala hedônica de nove pontos (1 - desgostei extremamente e 9 - gostei extremamente) (STONE; SIDEL, 1993), indicando o quanto os consumidores gostaram e desgostaram dos queijos Minas frescal produzidos com leite de cabra.

Para melhor conhecer o perfil dos avaliadores do queijo Minas frescal elaborado com leite de cabra, também foi solicitado aos 
avaliadores que respondessem a um questionário estruturado sobre a frequência de consumo de queijo Minas frescal em geral e a intenção de compra do queijo Minas frescal elaborado com leite de cabra, utilizando escala de atitude de 5 pontos (1 - certamente não compraria a 5 - certamente compraria) (MINIM, 2013).

As amostras foram servidas em uma única sessão, em cabines individuais, de forma simultânea, em copos descartáveis de $50 \mathrm{~mL}$, previamente codificados com números aleatórios de três dígitos, à temperatura aproximada de $7{ }^{\circ} \mathrm{C}$. Entre as avaliações, um copo de água foi servido para enxágue das papilas gustativas.

O teste foi realizado com 80 consumidores de queijo Minas frescal, com idade entre 18 e 40 anos, no laboratório de Análise Sensorial, no Campus Universitário do Araguaia - Universidade Federal do Mato Grosso, no período matutino e vespertino.

\section{Análise Estatística e Delineamento Experimental}

Os dados obtidos foram submetidos à análise de variância (ANOVA) sendo as médias de tratamento comparadas pelo teste de média Tukey $(\mathrm{p}<0,05)$ ou por regressão, quando a variável tempo foi significativa, através do programa computacional Sisvar 5.3 (FERREIRA, 2010). Os dados do questionário sobre hábitos de consumo foram apresentados em forma de distribuição de frequência.

Para o estudo da vida de prateleira do queijo Minas frescal de leite de cabra (T1 acidificação direta com adição de ácido lático e T2 - com adição da cultura starter mesofílica tipo O), o efeito do tempo de armazenamento em refrigeração foi analisado após 1,7 e 14 dias do produto embalado. As variáveis consideradas para vida de prateleira foram: $\mathrm{pH}$, acidez titulável em ácido lático e contagem de bactérias láticas totais.

\section{RESULTADOS E DISCUSSÃO}

\section{Caracterização microbiológica e físico- química do leite de cabra}

Os resultados das análises microbiológicas indicaram que o leite de cabra utilizado para produção do queijo Minas frescal estava dentro dos padrões estabelecidos tanto pelo Regulamento Técnico de Produção, Identidade e Qualidade do leite de cabra (BRASIL, 2000) e quanto pelo Regulamento

Tabela 1 - Caracterização microbiológica do leite de cabra

\begin{tabular}{c|c|c|c}
\hline Variáveis & Tratamento & Padrão & Resultados \\
\hline $\begin{array}{c}\text { Contagem de aeróbios mesófilos } \\
(\mathrm{UFC} / \mathrm{mL})\end{array}$ & $\begin{array}{c}\text { Leite } \text { in natura } \\
\text { Leite tratado termicamente }\end{array}$ & $\begin{array}{c}<5 \times 10^{5^{*}} \\
<5 \times 10^{4^{*}}\end{array}$ & $\begin{array}{c}4,4 \times 10^{3} \\
5,6 \times 10^{2}\end{array}$ \\
\hline $\begin{array}{c}\text { Leite } \text { in natura } \\
\text { Contagem de psicotróficos } \\
(\mathrm{UFC} / \mathrm{mL})\end{array}$ & - & $\begin{array}{c}1,8 \times 10^{2} \\
1,3 \times 10^{1}\end{array}$ \\
\hline $\begin{array}{c}\text { Coliformes Termotolerantes } \\
(\mathrm{NMP} / \mathrm{mL})\end{array}$ & Leite tratado termicamente & $<4 \times 10^{0^{* *}}$ & $<3,0 \times 10^{0}$ \\
\hline Salmonella $\mathrm{sp} .(\mathrm{em} 25 \mathrm{~g})$ & Leite tratado termicamente & Ausência ${ }^{* *}$ & Ausência \\
\hline
\end{tabular}

*Instrução Normativa $n^{\circ} 37$ de outubro de 2000, do Ministério da Agricultura, Pecuária e Abastecimento (BRASIL, 2000).

**Resolução RDC nº 12 de janeiro de 2001 (ANVISA, 2001). 
Técnico sobre os padrões microbiológicos para alimentos (ANVISA, 2001), não representando risco ao consumidor (Tabela 1).

A Tabela 2 apresenta o resultado das análises físico-químicas realizadas no leite de cabra.

Os resultados das análises físico-químicas indicaram que o leite de cabra utilizado para produção do queijo Minas frescal estava dentro dos padrões estabelecidos pelo Regulamento técnico de produção, identidade e qualidade do leite de cabra (BRASIL, 2000). Pequenas variações foram observadas para a caracterização físico-química do leite de cabra, entre os valores obtidos neste trabalho e os encontrados na literatura. A composição do leite de cabra varia de acordo com a raça, as condições ambientais, o estágio da lactação, a alimentação, os cuidados dispensados ao animal, o estado de saúde, a idade, a quantidade de leite produzido e a fisiologia individual do animal (AMARAL et al., 2011). Os valores encontrados para extrato seco total, gordura, $\mathrm{pH}$ e cinzas foram respectivamente de 11,5; 3,$4 ; 6,6$ e 0,8 (g/100 g) (Tabela 2). Gomes et al. (1997) ao estudarem os leites de cabra pasteurizado e congelado, obtiveram 11,03 $(\mathrm{g} / 100 \mathrm{~g})$ de extrato seco total, 2,7 (g/100 g) de gordura e pH de 6,6. Fernandes et al. (2008), analisando a variação centesimal do leite de cabras com dietas suplementadas, relataram, para leite de cabra sem a dieta, valores de 3,89 (g/100g) de gordura e 0,69 (g/100 g) de cinzas.

\section{Análises microbiológicas do queijo Minas frescal}

Os resultados das análises microbiológicas para a avaliação das condições higiênico-sanitárias dos queijos Minas frescal de leite de cabra estão apresentados na Tabela 3 , e demonstraram que as duas formulações

Tabela 2 - Caracterização físico-química do leite de cabra

\begin{tabular}{ccc}
\hline Variáveis & Padrão* $^{*}$ & Resultados \\
\hline Acidez $(\%$ de ácido lático, $\mathrm{m} / \mathrm{v})$ & 0,13 a 0,18 & 0,144 \\
$\mathrm{pH}$ & - & 6,60 \\
Extrato seco total $(\mathrm{g} / 100 \mathrm{~g})$ & - & 11,50 \\
Gordura $(\mathrm{g} / 100 \mathrm{~g})$ & Teor original & 3,40 \\
Cinzas $(\mathrm{g} / 100 \mathrm{~g})$ & $\geq 0,70$ & 0,80 \\
Densidade $\left(\mathrm{g} / \mathrm{cm}^{3}\right)$ & 1,0280 a 1,0340 & 1,030 \\
\hline
\end{tabular}

* Instrução Normativa no 37 de outubro de 2000, do Ministério da Agricultura, Pecuária e Abastecimento (BRASIL, 2000).

Tabela 3 - Caracterização microbiológica do queijo Minas frescal de leite de cabra

\begin{tabular}{cccc}
\hline Microrganismos & Padrão* & T1 & T2 \\
\hline S. aureus $(\mathrm{UFC} / \mathrm{g})$ & $<10^{3}$ & $9,6 \times 10^{2}$ & $4,9 \times 10^{2}$ \\
Coliformes termotolerantes (NMP/g) & $<5 \times 10^{3}$ & $<3,0$ & $<3,0$ \\
Salmonella sp. (em 25 g) & Ausência & Ausência & Ausência \\
Contagem de psicotróficos (UFC/g) & - & $1,1 \times 10^{3}$ & $7,1 \times 10^{3}$ \\
\hline
\end{tabular}

* Resolução RDC nº 12 de janeiro de 2001 (ANVISA, 2001).

T1 (acidificação com ácido lático) e T2 (acidificação com cultura mesofílica tipo O). 
encontravam-se em boas condições higiênicosanitárias e de consumo segundo a legislação (ANVISA, 2001).

\section{Caracterização físico-química do queijo Minas frescal}

A Tabela 4 apresenta os resultados das análises físico-químicas realizadas dos queijos Minas frescal.

Os resultados obtidos referentes às análises físico-químicas demonstram que os tratamentos não diferiram significativamente $(\mathrm{p}<0,05)$ entre si para todas as variáveis analisadas. Desta forma, o tipo de processamento não alterou a composição dos queijos que foram obtidos a partir dos mesmos ingredientes.

Segundo a legislação brasileira, o queijo Minas frescal é um queijo semi-gordo e de muito alta umidade, o que, em valores, deve ter entre 25,0 a $40,9 \%$ de matéria gor- da no extrato seco e umidade não inferior a $55,0 \%$ (BRASIL, 1997). Portanto, os queijos produzidos estão em consonância com o teor de umidade exigido na legislação. No entanto o teor de matéria gorda no extrato seco foi superior ao exigido pela legislação.

\section{Vida de prateleira dos queijos Minas frescal de leite de cabra}

A vida de prateleira dos produtos foi avaliada por 14 dias após da fabricação dos queijos. Em geral o queijo Minas frescal apresenta um período de estocagem de aproximadamente 21 dias de armazenamento refrigerado, porém neste estudo, para ambos os tratamentos (acidificação direta e fermentação com cultura lática) foi observado o crescimento de fungos no produto após o período de 14 dias de armazenamento refrigerado.

Tabela 4 - Caracterização físico-química dos tratamentos de queijo Minas frescal de leite de cabra

\begin{tabular}{ccc}
\hline Variáveis & T1 & T2 \\
\hline Umidade $(\mathrm{g} / 100 \mathrm{~g})$ & $62,70 \pm 0,89^{\mathrm{a}}$ & $62,30 \pm 0,62^{\mathrm{a}}$ \\
Gordura $(\mathrm{g} / 100 \mathrm{~g})$ & $18,00 \pm 0,95^{\mathrm{a}}$ & $19,20 \pm 0,64^{\mathrm{a}}$ \\
Gordura em base seca $(\mathrm{GBS} \mathrm{g} / 100 \mathrm{~g})$ & $48,25 \pm 0,95^{\mathrm{a}}$ & $50,92 \pm 0,64^{\mathrm{a}}$ \\
Cinzas $(\mathrm{g} / 100 \mathrm{~g})$ & $2,57 \pm 0,15^{\mathrm{a}}$ & $2,67 \pm 0,31^{\mathrm{a}}$ \\
\hline
\end{tabular}

Médias seguidas de letras iguais, na mesma linha, não diferem entre si pelo teste de Tukey a $5 \%$ de probabilidade $(\mathrm{p}<0,05)$.

T1 (acidificação com ácido lático) e T2 (acidificação com cultura mesofílica tipo O).

Tabela 5 - Teste de médias dos tratamentos de queijo Minas frescal de leite de cabra armazenados por 14 dias

\begin{tabular}{ccc}
\hline Variáveis & $\mathrm{T} 1$ & $\mathrm{~T} 2$ \\
\hline Contagem de Bactérias láticas (log UFC/g) & $4,68^{\mathrm{b}}$ & $7,39^{\mathrm{a}}$ \\
Acidez (\% de ácido lático) & $0,67^{\mathrm{b}}$ & $1,77^{\mathrm{a}}$ \\
$\mathrm{pH}$ & $6,03^{\mathrm{a}}$ & $5,20^{\mathrm{b}}$ \\
\hline
\end{tabular}

Médias seguidas de letras diferentes, na mesma linha, diferem entre si pelo teste de Tukey a $5 \%$ de probabilidade $(\mathrm{p}<0,05)$.

T1 (acidificação com ácido lático) e T2 (acidificação com cultura mesofílica tipo O). 
Os tipos de queijo Minas frescal e o tempo de armazenamento sob refrigeração afetaram significativamente a acidez, o $\mathrm{pH}$ e a contagem de bactérias láticas. Não houve interação entre os tratamentos e tempo de armazenamento.

A Tabela 5 apresenta o efeito dos tratamentos sobre as variáveis contagem de bactérias láticas, acidez e $\mathrm{pH}$.

A adição da cultura lática afetou significativamente a contagem de bactérias láticas em relação ao queijo Minas frescal por acidificação direta. Assim, consequentemente, a maior contagem de bactérias láticas resultou em maior acidez e menor valor de pH no queijo obtido por fermentação lática. Os resultados de acidez corroboram com os encontrados por Lourenço Neto (1998). O autor observou que a acidez titulável dos queijos Minas frescal com a adição de culturas probióticas (L. acidophilus, Bifidobacterium bifidus e Streptococcus thermophilus) foi maior do que com a adição de ácido lático.

A contagem de bactérias láticas encontrada no queijo por acidificação direta foi relacionado a algumas estirpes de bactérias láticas, as NSLAB do inglês, non starter lactic acid bactéria, presentes naturalmente no leite cru, que resistem ao tratamento térmico do leite (BERESFORD; WILLIAMS, 2004).

\section{Contagem de Bactérias láticas}

Os tratamentos com acidificação com ácido lático (T1) e com bactérias láticas (T2) apresentaram diferença significativa ( $p$ $<0,05)$ durante os 14 dias de estocagem na contagem de bactérias láticas totais. A Figura 1 ilustra a variação das contagens de bactérias láticas ao longo do tempo, sendo o modelo linear simples o mais adequado.

Em ambos os tratamentos, houve um aumento regular na contagem das bactérias láticas, variando aproximadamente, no queijo com acidificação direta, entre 3 e $6 \log \mathrm{UFC} / \mathrm{g}$, e no queijo com acidificação indireta, entre 5 e $8 \log \mathrm{UFC} / \mathrm{g}$. Observa-se, portanto, que a contagem de bactérias láticas totais, em ambos os tratamentos, permaneceu alta durante todo o período de armazenagem.

Esses resultados assemelham-se com outros estudos com bactérias láticas totais

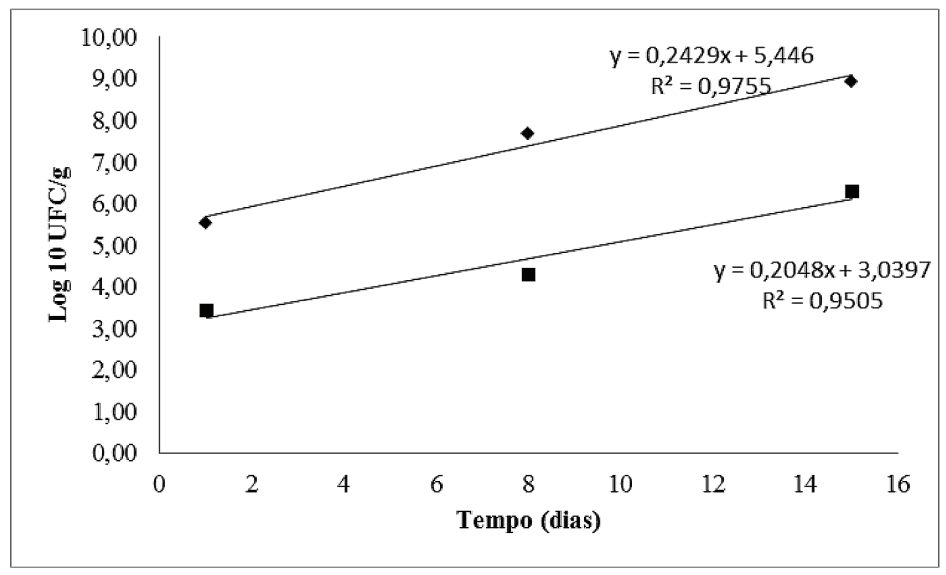

Figura 1 - Efeito do tempo de estocagem em relação às contagens de bactérias láticas nos diferentes tratamentos do queijo Minas frescal de leite de cabra ( $\boldsymbol{\text { T }} 1$ - acidificação com ácido lático e T2 - acidificação com cultura mesofílica tipo $\mathrm{O}$ ) 
encontrados na literatura. A contagem de Lactobacillus acidophilus avaliada por Alves et al. (2011) variaram entre 7,8 a $9 \log$ $\mathrm{UFC} / \mathrm{g}$ no queijo Minas frescal adicionado da cultura probiótica. Cichoski et al. (2008) quantificaram bactérias láticas no queijo Prato padrão e no queijo Prato com adição de $L$. rhamnosus. Com 30 dias de armazenagem, o queijo com probiótico apresentou $10^{8} \mathrm{UFC} / \mathrm{g}$, em torno de 2 ciclos logaritmos maior.

\section{Acidez}

A Figura 2 mostra a variação da acidez (\% de ácido lático) ao longo do tempo. A acidez dos queijos aumentou, sendo resultado do consumo da lactose residual presente nos queijos, que favorecem o desenvolvimento das bactérias láticas.

Os valores entre as duas formulações foram distintos durante toda a avaliação, obtendo uma variação de aproximadamente $11 \%$ durante o período de armazenagem. Essa diferença também foi observada por Lourenço Neto (1998) em queijos com a adição de culturas probióticas (L. acidophilus,
Bifidobacterium bifidus e Streptococcus thermophilus), sendo os valores de acidez maior do que com o queijo adicionado de ácido lático, com os valores, respectivamente, em torno de 0,60 e 0,45 (g de ácido lático/100g) no $21^{\circ}$ dia de armazenagem.

\section{pH}

Na Figura 3 está apresentada a variação do $\mathrm{pH}$ ao longo do tempo de armazenamento sob refrigeração.

Ao comparar os valores de $\mathrm{pH}$ das amostras no final da vida de prateleira com os valores obtidos no início, observa-se uma diminuição, evidenciando o mecanismo de pós-acidificação característico de culturas láticas. $\mathrm{O}$ acompanhamento do $\mathrm{pH}$ durante a estocagem do produto é um fator determinante nas características sensoriais do produto e de seu estado de conservação (OLIVEIRA et al., 2016). Entre os tratamentos, no último tempo de avaliação da vida de prateleira, houve variação de pH de 5,63 a 4,69, para o tratamento com acidificação com ácido lático e para o tratamento com acidificação com

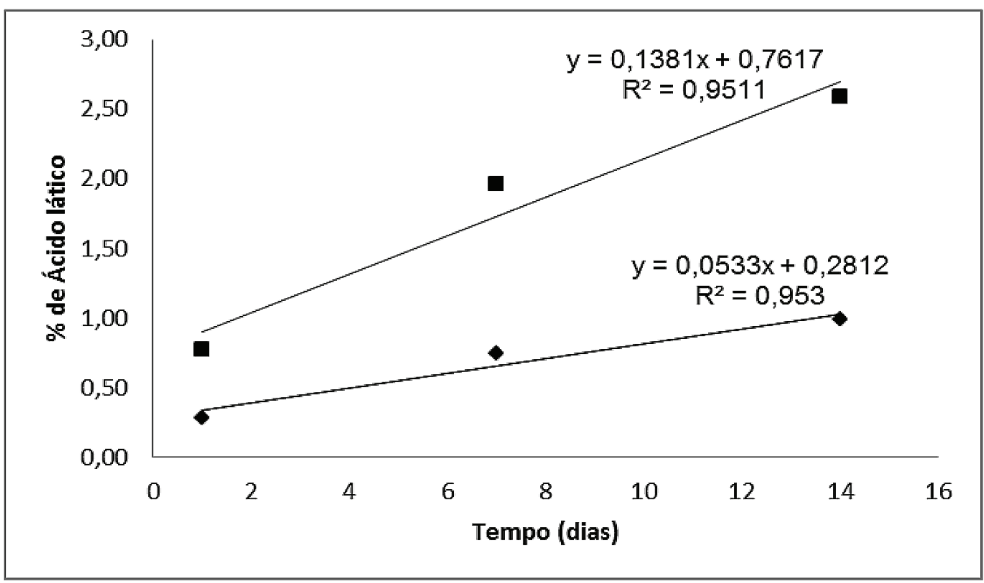

Figura 2 - Efeito do tempo de estocagem em relação aos teores de ácido lático nos diferentes tratamentos de queijo Minas frescal de leite de cabra ( T1 - acidificação com ácido lático e T2 - acidificação com cultura mesofílica tipo $\mathrm{O}$ ) 


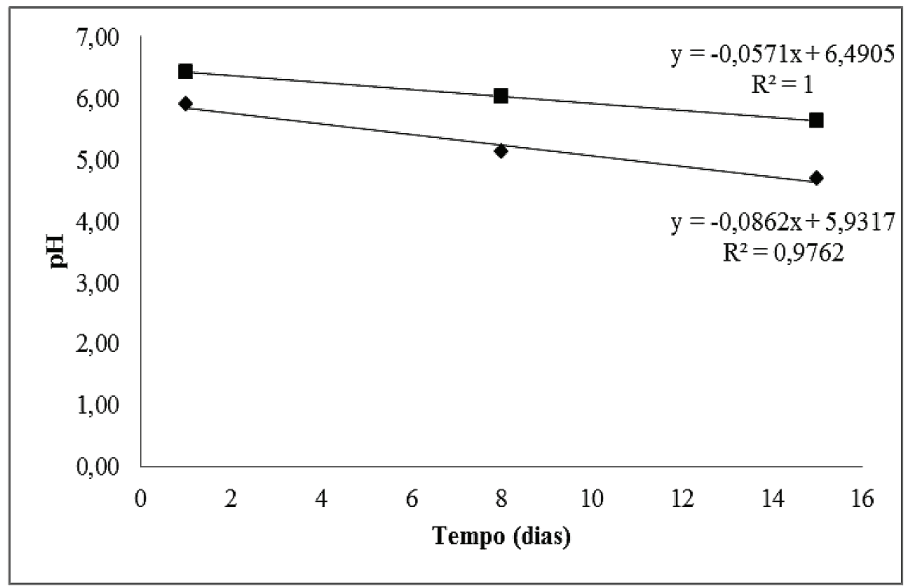

Figura 3 - Efeito do tempo de estocagem em relação aos valores de $\mathrm{pH}$ nos diferentes tratamentos de queijo Minas frescal de leite de cabra ( — T1 - acidificação com ácido lático e T2 - acidificação com cultura mesofílica tipo O)

bactérias láticas, respectivamente.

\section{Análise sensorial do queijo Minas frescal}

A Tabela 6 mostra os valores hedônicos médios dos atributos cor, aroma, sabor, textura e impressão global dos queijos Minas frescal elaborados com diferentes formas de acidificação, avaliados pelos consumidores após 5 dias de processamento.

Os tratamentos diferiram significativamente entre si $(p>0,05)$ em relação aos atributos sensoriais avaliados. O queijo Minas frescal obtido por acidificação direta (T1) apresentou maiores escores médios para todos os atributos avaliados, sendo o mais aceito pelos consumidores, situando na região de aceitação, ou seja, entre os termos hedônicos gostei ligeiramente e gostei extremamente (Tabela 6). Verificou-se que a acidificação direta, por ter um aumento menos acentuado na concentração de ácido lático, resultou em maior aceitação sensorial do produto pelos consumidores. Alves et al. (2011), ao avaliarem a aceitação do queijo Minas frescal com adição de Lactobacillus acidophilus e o queijo Minas frescal com adição de ácido lático, obtiveram maiores médias no tratamento com a cepa probiótica. O mesmo resultado foi encontrado no trabalho de Buriti

Tabela 6 - Valores médios das notas hedônicas dos atributos sensoriais obtidos pelo teste de aceitação dos queijos Minas frescal de leite de cabra

\begin{tabular}{cccccc}
\hline Formulação & Cor & Sabor & Aroma & Textura & Impressão global \\
\hline T1 & $8,2^{\mathrm{a}}$ & $7,9^{\mathrm{a}}$ & $7,4^{\mathrm{a}}$ & $8,1^{\mathrm{a}}$ & $8,0^{\mathrm{a}}$ \\
T2 & $8,0^{\mathrm{b}}$ & $5,9^{\mathrm{b}}$ & $6,6^{\mathrm{b}}$ & $6,8^{\mathrm{b}}$ & $6,6^{\mathrm{b}}$ \\
\hline
\end{tabular}

* Médias seguidas de letras diferentes, na mesma coluna, diferem entre si pelo teste de Tukey a $5 \%$ de probabilidade.

T1 (acidificação com ácido lático) e T2 (acidificação com cultura mesofílica tipo O). 
et al. (2005), que também reportaram maior média para o queijo Minas frescal adicionado da cultura probiótica.

Dos consumidores que avaliaram as amostras de queijo Minas frescal de leite de cabra, 35,8\% afirmaram já terem consumido outros produtos lácteos provenientes de outras espécies animais diferentes da espécie bovina, e desses, $90 \%$ disseram ter gostado da experiência.

A intenção de compra dos dois tratamentos de queijo Minas frescal de leite de cabra em uma escala de 1 a 5 , variando de certamente não compraria a certamente compraria está apresentada na Tabela 7. A amostra com acidificação direta (T1) teve maior intenção de compra em relação à amostra com acidificação por fermentação lática (T2) (p $<0,05)$, sendo avaliada pelos consumidores como "provavelmente compraria". Esse resultado confirma a preferência dos avaliadores indicada no teste de aceitação (Tabela 6).

Tabela 7 - Intenção de compra do queijo Minas Frescal de leite de cabra

\begin{tabular}{cc}
\hline Formulação & Intenção de compra \\
\hline T1 & $4,6^{\mathrm{a}}$ \\
T2 & $3,1^{\mathrm{b}}$ \\
\hline
\end{tabular}

A boa aceitação e intenção de compra do queijo Minas frescal produzido com leite de cabra, em ambos os tratamentos, pode ser devido ao consumo periódico de queijos e, este em especial, por ter como base o leite de cabra, que além de atribuir sabor diferenciado, pode ser consumido por pessoas alergênicas ao leite de origem bovina.

\section{CONCLUSÕES}

Os queijos Minas frescais com leite de cabra produzidos por acidificação direta e por fermentação com bactérias não diferiram em relação ao teor de umidade e gordura, porém a forma de acidificação do produto afetou a acidez, o pH e a aceitação sensorial. O queijo obtido por acidificação direta apresentou menor acidez e $\mathrm{pH}$ e maior aceitabilidade sensorial pelos consumidores quando comparado ao queijo obtido por fermentação lática. Independente da forma de acidificação, a produção do queijo Minas frescal com leite de cabra mostrou-se viável, com uma boa aceitabilidade sensorial e intenção de compra, demonstrando ser uma alternativa para agregar valor à matéria-prima, leite de cabra, pela indústria láctea e uma potencial alternativa aos consumidores alérgicos ao leite bovino.

\section{REFERÊNCIAS}

AGÊNCIA NACIONAL DE VIGILÂNCIA SANITÁRIA (ANVISA). Resolução de Diretoria Colegiada, RDC $\mathrm{n}^{\circ} 12$, de 02 de janeiro de 2001. Aprova o Regulamento Técnico sobre padrões microbiológicos para alimentos. Diário Oficial da República Federativa do Brasil, Brasília, 10 jan. 2001.

ALFÉREZ, M. J. M. et al. Digestive utilization of goat and cow milk fat in mal absorption syndrome. Journal of Dairy Research, v. 68, n. 3, p. $451-461,2001$.

ALVES, C. C. C. et al. Utilização de Lactobacillus acidophilus e de acidificação direta na fabricação de queijo de Minas frescal. Arquivo Brasileiro de Medicina Veterinária e Zootecnia, n. 6, p. 1559-1566, 2011.

ALVES, L. S. et al. Yield, changes in proteolysis, and sensory quality of Prato cheese produced with different coagulants. Journal of Dairy Science, v. 96, n. 12, p. 74907499, 2013.

AMERICAN PUBLIC HEALTH ASSOCIATION (APHA). Compendium of methods 
for the microbiological examination of foods. Washington, DC, $4^{\mathrm{a}}$ ed., 2001. 676p.

AMARAL, D. S., AMARAL, D. S., NETO, L. G. M. Tendências de consumo de leite de cabra: enfoque para melhoria da qualidade. Revista Verde, v. 6, n. 1, p. 39-42, jan./mar, 2011.

BERESFORD, T.; WILLIAMS, A. The microbiology of cheese ripening. In: FOX, P. F. ET AL. (Ed.). Cheese chemistry, physics and microbiology, $3^{\mathrm{a}}$ ed. Amsterdam: Elsevier, 2004, p. 287-317, v. 1, General Aspects.

BRASIL. Ministério da Agricultura, Pecuária e Abastecimento. Portaria $n^{\circ} 146$, de 07 de março de 1996. Aprova os Regulamentos Técnicos de Identidade e Qualidade de Queijos. Diário Oficial da República Federativa do Brasil, 11 mar. 1996. Seção 1, Página 3977.

BRASIL. Ministério de Agricultura, Pecuária e Abastecimento. Portaria $n^{\circ} 352$, de 04 de setembro de 1997. Aprova o Regulamento Técnico de Identidade e Qualidade de queijo Minas frescal. Diário Oficial da República Federativa do Brasil, 8 set. 1997. Seção 1, Página 19684.

BRASIL. Ministério da Agricultura, Pecuária e Abastecimento. Instrução Normativa $\mathrm{n}^{\mathrm{o}} 37$ de 31 de outubro de 2000. Aprova o Regulamento Técnico de Identidade e Qualidade de Leite de Cabra. Diário Oficial da República Federativa do Brasil, 08 nov. 2000.

BURITI, F. C. A.; ROCHA, J. S.; SAAD, S. M. I. Incorporation of Lactobacillus acidphilus in Minas fresh cheese and its implications for textural and sensorial properties during storage. International Dairy Journal, v. 15, n. 12, p. 1279-1288, 2005.
CHAVES, K. S., GIGANTE, M. L. Prato cheese as suitable carrier for Lactobacillus acidophilus La5 and Bifidobacterium Bb12. International Dairy Journal, v. 52, p. 10$18,2016$.

CICHOSKI, A. J. et al. Efeito da adição de probióticos sobre as características de queijo prato com reduzido teor de gordura fabricado com fibras e lactato de potássio. Ciência e Tecnologia de Alimentos, v. 28, n. 1, p. 214-219, 2008.

COELHO, M. O. L. C. Variabilidade das características do leite de cabra e sua influência no fabrico de queijo. 2012. 87f. Dissertação (Mestrado em Engenharia Zootécnica) - Instituto Superior de Agronomia, Universidade Técnica de Lisboa, Lisboa, 2012.

CORREIA, R. T. P.; BORGES, K. C. Posicionamento do consumidor frente ao consumo de leite de cabra e seus derivados na cidade de Natal-RN. Revista do Instituto de Laticínios Cândido Tostes, v. 366, n. 64, p. 36-43, 2009.

FERNANDES, M. F. et al. Características físico-químicas e perfil lipídico do leite de cabras mestiças Moxotó alimentadas com dietas suplementadas com óleo de semente de algodão ou de girassol. Revista Brasileira de Zootecnia, v. 37, n. 4, p. 703-710, 2008.

FERREIRA, D. F. Sisvar: versão 5.3, DEX/ UFLA, Lavras: UFLA, 2010.

GOMES, M. I. F. V. et al. Características químicas, microbiológicas e sensoriais de leite de cabra congelado. Ciência e Tecnologia de Alimentos, v. 17, n. 2, p. 111-114, mai/ ago, 1997.

INSTITUTO ADOLFO LUTZ (IAL). Normas 
analíticas do Instituto Adolfo Lutz: métodos químicos e físicos para análise de alimentos. $4^{\mathrm{a}}$ ed., Editora Adolfo Lutz, São Paulo, 2005.

LOURENÇO NETO, J. P. Uso de culturas láticas na fabricação de queijo Minas frescal como alternativa de melhoria de qualidade. In: Seminário Internacional de queijos frescos, 1., 1998, São Paulo. Anais... São Paulo, 1998. p. 59-75.

MINIM, V. P. R. Análise sensorial: estudos com consumidores. $3^{\text {a }}$ ed. Viçosa: Editora UFV, 2013. 332 p.

OLIVEIRA, K. M. O. et al. Goat milk frozen yogurt cajá (Spondias mombin L.) flavor: development and sensory acceptance of exotic food. Current Nutrition \& Food Science, v. 12, n. 2, p. 105-112, 2016.

PARK, Y. W. Bioactive Components in Goat Milk. In: PARK, Y. W. (Ed.), Bioactive Components in Milk and Dairy Products. Singapore: Wiley-Blackwell, 2009. p. 43-82.

QUEIROGA, R. C. R. E. et al. Elaboração e caracterização físico-química, microbiológica e sensorial de queijo "tipo minas Frescal" de leite de cabra condimentado. Revista de Ciências Agronômicas, v. 40, n. 3, p. 363372, 2009.
ROSA, V. P. Efeitos da atmosfera modificada e da irradiação sobre as características microbiológicas, físico-químicas e sensoriais do queijo Minas frescal. 2004. 155f. Dissertação (Mestrado em Ciência e Tecnologia de Alimentos) - Escola Superior de Agricultura "Luiz de Queiroz". Universidade de São Paulo, Piracicaba, 2004.

SANTOS, K. M. O. et al. Processo de fabricação de queijo Minas frescal probiótico elaborado com leite de cabra: prática/processo agropecuário. Sobral: Embrapa Caprinos e Ovinos, dez. 2009. 7p. (Comunicado Técnico 104).

SCOT CONSULTORIA. Aumenta o consumo de queijo no Brasil. Disponível em: $<$ https://www.scotconsultoria.com.br/leite/ mercado-leite/161/aumenta-o-consumo-dequeijo-no-brasil.htm>. Acesso em: 03 jul. 2014.

STONE, H.; SIDEL, J. L. Sensory evaluation practices. $2^{\mathrm{a}}$ ed. Orlando Flórida: Academic Press. 1993. 338p.

VIANNA, P. C. et al. Microbial and sensory changes throughout the ripening of Prato cheese made from milk with different levels of somatic cells. Journal of Dairy Science, v. 91, n. 5, p. 1743-50, 2007. 